\title{
Writing for Publication in Informatics and Data Science in Clinical Research
}

\author{
Richard F. Ittenbach ${ }^{* \dagger}$ and William A. Ittenbach ${ }^{\dagger}$
}

Clinical data management and its contemporary analogs, clinical research informatics and clinical data science, constitute a small but rapidly growing specialty within the broader field of biomedical science. As such, the literature base is evolving, drawing heavily from the larger and more established disciplines of biomedical informatics, biostatistics, clinical operations, and regulatory affairs. The purpose of this article is to offer a rationale for, guidance on, and an invitation to individuals interested in submitting their research to the Journal of the Society for Clinical Data Management: Informatics and Data Science in Clinical Research.

Keywords: scientific writing; clinical research; data science; publishing; clinical data management

Clinical research can be a challenging and sometimes fruitless process, but it can also be fun and highly rewarding. At the heart of this process is the challenge of formulating and answering a difficult question of scientific and health-related interest. That challenge often extends to systems-wide processes that, if dealt with appropriately, can dramatically accelerate the pace of research. The purpose of this article is to offer a rationale for, guidance on, and an invitation to individuals interested in submitting their research to the Journal of the Society for Clinical Data Management: Informatics and Data Science in Clinical Research (JSCDM). Principles raised in this article are directly applicable to other peerreviewed journals as well.

\section{Writing for publication}

Professional writing, in and out of the sciences, assumes a logical flow of information that tells a meaningful story from beginning to end, in clear language, with good grammar and sound syntax. Scientific writing is a specific type of professional writing that moves science forward, using criteria deemed valuable to a scientific discipline. Because of this, scientific writing has its own culture, norms, and style, which may vary by journal but tends to be relatively consistent within a particular scientific discipline. Fields have their own preferences for the ways in which information should be presented and clear expectations for what qualifies as a good article.

\footnotetext{
* Cincinnati Children's Hospital, Department of Pediatrics, University of Cincinnati College of Medicine, US

Cincinnati, $\mathrm{OH}$, US

Corresponding author: Richard F. Ittenbach, PhD

(richard.ittenbach@cchmc.org)
}

Underlying the biomedical sciences is a wide range of technical specialties and subspecialties that facilitates scientific progress. A defining feature of the scientific specialties is an emphasis on methodology-the rigorous means by which problems are investigated and new knowledge is generated. Research in clinical data management, research informatics, and clinical data sciences are no exception. From clinical trials to observational studies, it is the emphasis on rigorous study design methodology and adequate data quality that allow investigators to stand behind their findings with confidence. To that end, JSCDM articles encompass a wide range of data methods and processes relevant to clinical research.

Writing about research is different from conducting it, yet writing remains crucial to the research process. Without the written report, a study's influence on the field may be fleeting. Even with tremendous results, without a written account of the methods, results, and implications that have been vetted by professionals in the field, the findings are not likely to markedly influence practice. That was the case of Gregor Mendel's early work in genetics. As groundbreaking as his work was, it went largely unnoticed for more than 30 years before it received the recognition it merited. ${ }^{1}$ Where would precision medicine be today if Mendel's work had been shared and fully utilized by others many decades earlier? That same concept can be applied to today's work for both positive (promising, significant) findings as well as negative (nonsignificant) findings to help clinical research informatics and data science researchers know where to focus their efforts. In the case of applied research informatics and clinical data science, that would now be in JSCDM. 


\section{What makes an article scientific?}

A scientific article is a special kind of article that describes the steps used to study a problem of scientific interest. Within most scientific disciplines this knowledge is enculturated early on into the training, but in clinical research informatics, clinical data management, and clinical data science, this concept still needs nurturing. A scientific article should convey both the rationale for a study and the processes and methods used. Findings drawn from other published studies must be cited and contained in the reference list. Articles must be wellwritten and free of unnecessary jargon, presenting just the facts needed to convey the essentials of the study. New authors are encouraged to seek guidance from experienced authors prior to submitting their work for publication; they may even request mentoring through JSCDM's editorial process.

Clinical research today and the articles that come from it closely follow the same scientific method introduced to students of all ages worldwide. Surprisingly, it is basically the same scientific method first described by Aristotle more than 2,300 years ago. ${ }^{2}$ This straightforward method makes it easy for researchers at all levels of experience to study problems and to find answers to even the most perplexing questions, including questions about the safety and efficacy of new therapeutics and the methods by which they are pursued.

The method is simple, logical, and walks the researcher through an otherwise complex process. For today's scientists, like those of Aristotle's time, the scientific method serves as the bridge between language, thought, and observable reality (see Figure 1).

Scientific articles are written using specific criteria, typically stipulated by the journal, and often referred to as author or manuscript guidelines. Some journals are strict, while others are less so. Because the research process varies across disciplines and study designs, journal editors need to have a consistent structure with which to evaluate submissions. These guidelines often include such things as editorial style, formatting (font, text size, margins, page limits), and specifics regarding tables, figures, and references. The challenge for researchers who submit their work to different journals is to find ways to keep their sanity as they move from journal to journal.
JSCDM has chosen to have a strict but limited number of submission criteria to strike a blend between flexibility and consistency in reporting (https://www.jscdm.org/).

\section{Writing for the Journal of the Society for Clinical Data Management \\ Why write for JSCDM?}

For some researchers, scholarship is a life-long ambition and the writing process comes quite easily, including finding the right journal. For others, finding the right journal can be almost as difficult as writing the paper. Some may ask, "Why take time out of a really busy day to write for JSCDM?" The answer is severalfold but begins with the premise that, historically, data management and data science have had a fragmented literature base to help guide their scholarly work.

First, clinical research informatics and clinical data science are new fields and still evolving as a collective discipline. Today's publications can absolutely influence the direction of the field for years to come. ${ }^{3}$ Second, change comes quickly and gets rolled out broadly in today's data intensive world. Researchers' and clinicians' need to know will be matched by JSCDM's ability to deliver. The fact that JSCDM is an electronic, open access journal means the articles are free of charge and open to everyone regardless of subscription status, move right into production upon acceptance, and are immediately available to the entire scientific community. Third, there is a rich literature base in biomedical informatics and its applications, yet the issues of data quality, data management, information governance, organizational integration, and even data policy have represented a minority interest in established journals. JSCDM will fill a specific and immediate gap in the biomedical literature.

What will make JSCDM so valuable to readers is that it will serve as a resource for scientists practicing at the intersection of other highly complex disciplines: biomedical informatics, biostatistics, clinical operations, and regulatory affairs. For data scientists and researchers who work in this area, no outlets have integrated the knowledge bases in the way that JSCDM will. The journals that have targeted this area previously have only tangentially served the research needs of data managers and data scientists on the front lines of day-to-day

\section{(1) > Observe}

Observe a problem in the real world requiring investigation of interest well and evaluate it

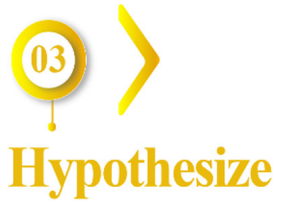

Formulate a hypothesis about expected results Define the proble enough to measure

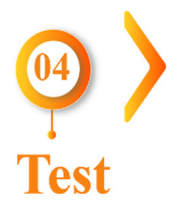

Collect and manage data, analyze using scientifically rigorous methods

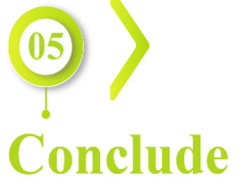

Summarize findings, draw conclusions, and share with the scientific community

Figure 1: Scientific Method. 
operations. As the field matures, thought leaders from other disciplines are increasingly turning to ours for guidance. We must have the practical and theoretical frameworks in place to support not only our field's advancements, but also those of other, related sciences.

There are several defining criteria for a scientific discipline. Most importantly, the discipline must be grounded in a specific knowledge base with a theoretical foundation that supports its practical contributions. The field's active literature base offers a repository for its newest discoveries. But the discipline must also have training programs to prepare the next generation of professionals. The professional literature nourishes this training. Finally, the literature base connects a specific field to other, related disciplines. Peer-reviewed literature, such as journals and textbooks, are, in essence, a profession's best assurance that a field's literature base is held to high standards. While important by any measure, peer-reviewed publications are not the only form of scholarship. Other publications, such as book chapters, monographs, white papers, and training documents, are also important and offer breadth and depth to a field's knowledge base. These scholarly works are generally available through other avenues, such as professional societies and academic presses.

\section{Benefits}

Writing to help the field advance is an important contribution to science, but writing also has many professional benefits. For some, it is a requirement of the job; for others, the writing process itself, helping others with their research, or investigative teamwork brings them joy. At a deeper level, one may feel the importance of conveying information about what they have done so that others do not have to travel the same path. In fact, one's personal reasons could be as important and influential as the professional reasons.

Perhaps the simplest and most obvious reason for a person to write a scientific paper is the learning that comes with it-digging deep into the literature and comparing one's ideas and words with others'. No matter how much a person knows about a given topic, there is always more to learn. Just as a field's knowledge base changes, so too can an individual's. Writing for others requires making certain that what we are saying is true, or as true as we know it to be at the time. In essence, that is what science is all about: the pursuit of truth. The best writers take extra care to write their findings in a way that is as easy to understand as possible. In sum, the writing process forces us to reconcile our thoughts and assumptions with the published work of others.

That deeper level of understanding about scientific data and the operational processes that support them do not just make better scientists, they also make better clinicians, employees, and team players, professionals others can turn to for help when solving problems. Generally, people who write about a given topic are viewed by others as problem solvers. That includes proposing solutions to organizational as well as scientific problems. Writing is a valued process, but attacking a problem scientifically and writing it up for peer review by experts in the field adds a level of scrutiny that inspires confidence that the data, the processes, and the knowledge derived from them are trustworthy and useful.

Additionally, a person might wish to pursue scientific writing because it helps with their own marketability. For the same reason that readers look to others who have published professionally for advice when attempting to solve a problem, so, too, do employers. Employers value employees who study problems, and they particularly value those who are willing to solve problems believed to be important to the field-especially because scientists willing to write for technical journals under the affiliation of their institution's name generally bring positive attention to the institution. If the research continues, many researchers are sought after to help lead other efforts in professional, civic, and even governmental initiatives.

\section{Requirements of JSCDM articles}

The mission of the Society for Clinical Data Management (SCDM) is to "connect and inspire professionals managing global health data" through thought leadership, education, and advocacy. ${ }^{4}$ From its origin as a professional society in 1994 , SCDM has chosen to lead by emphasizing strong, insightful scholarship from its members and those of allied professions. In short, JSCDM strives to be the journal of choice for those practicing in the world of clinical research informatics, clinical data management, and clinical data science. With its worldwide editorial team, JSCDM is well positioned to evaluate and share the highest quality research available in the care and treatment of clinical research data today. While JSCDM is open to all forms of clinical research, traditional as well as innovative, the journal is currently encouraging the following types of research:

- Original Research: report of a scientific investigation unique to the professional literature and conducted using innovative, well-articulated study designs

- Review Articles: systematic reviews, meta-analyses, quantitative and qualitative syntheses of the professional literature

- Design Articles: reports on innovative study designs and methods, including evaluation and validation studies that have been used previously or are under development

- Case Studies/Demonstration Projects: in-depth reports of a novel approach, application, technology, or process used or perceived to be of value in the clinical data sciences

- Educational/Professional Development: reports on the structure, analysis, delivery, or evaluation of instructional methods or programs

- Topic Briefs and Perspectives: in-depth perspectives on new policies, regulations, or technologies deemed important to the field

As with other journals, it is not simply about the type of article so much as it is the insightful innovation that can influence practice. The point is that data science comprises 
many types of research. While data science must adhere to the rules of science, not all science-and especially not all data science-is hypothesis driven. While hypothesis driven research is considered the gold standard in clinical research, some studies may actually produce hypotheses, while other will be descriptive, instructional, or even philosophical in nature. Some will be atheoretical and data driven, while others may be driven by ethical and moral problems of the day, such as confidentiality of records, definition of adverse events, and selection of specific learning algorithms. JSCDM is devoted to publishing research deemed relevant to the field and looks forward to receiving manuscripts that embody the spirit, quality, rigor, and creativity of today's breakthrough methods in the clinical data sciences.

Rigor, to many researchers, means adhering closely to the scientific method. But given the applied and translational nature of the field, there is likely to be tension among the various methods used, even in the best of studies. That is not only expected but also encouraged by JSCDM-thinking in new and different, yet equally rigorous, ways. That means bringing together existing sciences and schools of thought to create new ones for the betterment of all-this is the essence of translational research. ${ }^{5}$ The field's methods must not only follow but facilitate its development. Take for instance systematic literature reviews, once thought of as a prelude to an experimental study but now viewed as a methodology all its own. Similarly, evaluation studies previously only used in education and the social sciences are now highly regarded in industry, environments in which clinical research informatics and clinical data science are responsive. Whatever the approach, all studies must be conducted and written up using standards of best practice. JSCDM authors will be expected to report their studies in accord with professionally sanctioned guidelines, such as CONSORT (clinical trials), PRISMA (meta-analyses), STROBE (observational studies), and CHERRIES (surveys) guidelines, among others. ${ }^{6}$

\section{Editorial process}

The purpose of a professional journal is to disseminate cutting edge research that can be used by professionals throughout the entire discipline. Good writing is a valuable skill for all forms of communication, but for scientific writing it is paramount. The written word is often the foundation for a new line of research or a marked change of direction. Now, more than ever, journals are under pressure to make their information available to readers quickly so that the research can be adopted in as close to real time as possible. As such, that means the editorial process must occur quickly, carefully, and with utmost attention to detail. For this to happen, manuscripts must be written in a style and format that allows them to be reviewed quickly by a team of reviewers. For JSCDM, that means all submissions will initially be reviewed by a staff member in the editorial office and a decision reached within a week regarding appropriateness of content and scholarship. If successful at this stage, the managing editor will forward the paper to an associate editor to manage the review process, which generally takes about two weeks and includes up to three expert reviewers who are experienced practitioners and academic researchers well-versed in the area.

To assist with all phases of the review process, from writing, to reviewing, to post-publishing evaluation, journals require submissions to conform to a specific style. Because of clinical research informatics' and clinical data science's importance to the biomedical community, JSCDM requires all submissions conform to the American Medical Association format for writing. ${ }^{7}$ The AMA Manual of Style goes well beyond writing mechanics and offers important guidance on study design characteristics, sections of a manuscript (e.g., Methods, Results, Discussion), references, figures, tables, and appendices. The AMA style manual also offers guidance on such important elements as tone, tense, and voice needed for communicating one's message in a clear and professionally appropriate manner. Additional resources are available to help with writing and are referenced elsewhere. ${ }^{8}$

While a technically well-written paper helps with readability and conveyance of information, that is not a guarantee. Even the most well-written articles will be of little value to readers if they lack relevance. A key consideration in relevance is meaningfulness to the research community. The difficult part is that it is not always certain who constitutes the community. As such, writers are encouraged to write with both precision and generalizability-or provide examples of application-to appeal to those outside the field of interest. For clinical data managers and clinical data scientists, that is likely to include scientists and practitioners not only from this field, but also from closely related fields, such as biomedical informatics, biostatistics, clinical operations, and regulatory science.

\section{Writing the (Not So) Perfect Article}

Writing a paper that other scientists use in their own work is never an easy task. Successful manuscripts have several characteristics in common. First, and perhaps most importantly, authors must know their audience and understand what their audience needs and expects to see in a publication. Manuscripts that are not well written are particularly irritating to readers, especially reviewers, and receive less attention even when their results are good. JSCDM's readers represent many different backgrounds and areas of training; hence, authors should strive to articulate clearly all parts of their paper so that readers who are not completely familiar with a topic can understand the essential details. Writing typically comes most easily to those who are passionate about their topic, so JSCDM encourages its authors to write about topics they find challenging and truly enjoyable. Here too lurks a danger: passion can get in the way of clarity.

According to William Zinsser, author of On Writing Well, the secret to good writing is to "strip every sentence down to its cleanest components". ${ }^{9}$ If words do not serve an important function, then do not use them. Writers should be clear about the purpose of their paper, the methods that were used (sample, data, processes and materials, analyses), the results obtained (which in many cases will 
be the smallest section of the report), and what the results mean for the field.

Second, a major challenge for today's clinical researchers is finding a balance between making their reports parsimonious while providing sufficient detail to render their work reproducible. Many disciplines have "crises of replicability and of reproducibility," especially in the life and human sciences. ${ }^{10}$ It is expected that the data from a study will be made available upon request or through a third-party repository so the results can be recomputed and confirmed by independent researchers. Moreover, the methods themselves must be sufficiently well described to allow for the reproducibility of results.

Third, the material presented should be as recent and accurate as possible. Admittedly, research often comes in waves, sometimes with long periods of apparent inactivity. In new areas of science there may be no literature at all to draw upon. Either way, simply taking what is available or what supports a specific premise without direct relevance or authenticity does not represent best scientific practice. Outdated information may be misleading or even wrong and may delay scientific progress. If intentionally used, it can even hurt the reputation of a scientist or institution. Something as simple as confusing lay publications with peer-refereed publications or failing to distinguish between primary and secondary sources can quickly undermine the integrity of a paper. The ultimate criteria then are trust, documentation, and verification through one's methods, writing, and sources.

\section{Writing is a skill that can be learned}

Scientific writing is not just for the literary elite. In fact, it is for anyone and everyone who conducts research at any level. Writing up one's research and submitting it for publication is the final piece of the research process. It is a skill that can and must be learned, and in some cases relearned and refined throughout one's career. Two oftenused excuses for why someone does not write is that they "just don't have it" or "don't have the time."

Like any skills worth having, getting better at writing requires time and energy. It must be a priority. Scientific writing can be an exciting and rewarding process, but it is also a competitive one in which writers must convince journal editors that their paper is important and timely. There is a limited number of pages in each journal, and editors must choose which manuscripts will be of greatest interest to their readers. Although acceptance rates vary tremendously, acceptance rates of leading journals can be as low as $5 \%$ to $10 \%$ of all submissions. ${ }^{11,12}$

Despite its challenges, scientific writing is also a social process, one that brings together writers and reviewers for a common purpose: getting the best research into the professional literature. Skarupski recommends writing accountability groups to keep researchers motivated and on schedule. ${ }^{13}$ According to Skarupski, there is nothing magical about scientific writing, it is just a matter of practice.

Because writing requires practice to become good, it helps to have strategies. The first strategy is to set aside time daily or weekly to write. If a researcher has a writing group to help with this expectation, even better. Routine assures practice, which assures progress. Second, writing about topics that a researcher is familiar with-or wants to become familiar with-is important to the process. Writing about unfamiliar topics or problems makes it difficult to distinguish quality content. Third, one must be as patient with one's skills as with the development of the article. The more time spent writing, the easier it will be for readers to understand. Compare taking a class from a wellprepared teacher versus an unprepared one: there are rare, gifted teachers who can teach virtually anything with little preparation, but for the majority, thorough preparation is the only route to successful instruction. Finally, get others to proofread your paper before submission: the more eyes on the paper the better. Not only are they likely to make your paper better, but also they are likely to catch things the reviewers would have caught anyway.

\section{Conclusion}

The purpose of this article is to offer a rationale for, guidance on, and an invitation to individuals interested in submitting their research to the Journal of the Society for Clinical Data Management: Informatics and Data Science in Clinical Research. JSCDM has a two-fold mission to promote rigorous, scholarly research that not only moves the fields of clinical research informatics and clinical data science forward, but also offers research that is applicable and accessible to today's practitioners. More specifically, JSCDM fills a void in the applied research informatics and clinical data science literature by connecting today's practitioners with scholars from around the world to improve clinical research. We welcome authors from all disciplines to be a part of this important and exciting journey.

\section{Acknowledgements}

The authors wish to offer our sincerest appreciation to the following individuals for their insightful comments and suggestions regarding the development of this manuscript: Dr. Heidi Sucharew, Dr. Vadim Tantsyura, Dr. Meredith Zozus, Ms. Ginger Ittenbach, and our two anonymous reviewers.

\section{Competing Interests}

The authors have no competing interests to declare.

\section{References}

1. Zwart H. Pea Stories. Why was Mendel's Research Ignored in 1866 and Rediscovered in 1900? In: Understanding Nature. 2008: 197-231. Springer. DOI: https://doi.org/10.1007/978-1-40 20-6492-0_9

2. Taylor A. Aristotle. Rev ed. Dover; 1955.

3. Obermeyer Z, Emanuel EJ. Predicting the future-big data, machine learning, and clinical medicine. The New England Journal of Medicine. 2016; 375(13): 1216. DOI: https://doi.org/10.1056/ NEJMp 1606181

4. Society for Clinical Data Management. Journal of the Society for Clinical Data Management (JSCDM). Author. Published 2020. Accessed December 10, 2020. https://www.jscdm.org/. 
5. Zerhouni EA. Translational and clinical science-time for a new vision. New England Journal of Medicine. 2005; 353(15): 1621. DOI: https://doi.org/10.1056/ NEJMsb053723

6. UK EQUATOR Centre. Ehancing the quality and transparency of health research. University of Oxford. Published 2020. Accessed December 10, 2020. https://www.equator-network.org/about-us/ uk-equator-centre/.

7. Christiansen SL, Iverson C. AMA Manual of Style: A Guide for Authors and Editors. 11th ed. Oxford University Press; 2020. DOI: https://doi. org/10.1093/jama/9780190246556.001.0001

8. International Committee of Journal Medical Editors (ICJME). Preparing a Manuscript for Submission to a Medical Journal. Published 2021. Accessed April 14, 2021. http://www.icmje.org/ recommendations/.

9. Zinsser W. On Writing Well: The Classic Guide To Writing Nonfiction. Harper Collins; 2006.
10. Munafò MR, Nosek BA, Bishop DV, et al. A manifesto for reproducible science. Nature Human Behaviour. 2017; 1(1): 1-9. DOI: https://doi.org/10.1038/s41562-016-0 021

11. Björk B-C. Acceptance rates of scholarly peer-reviewed journals: A literature survey. El profesional de la información; 2019. DOI: https:// doi.org/10.3145/epi.2019.jul.07

12. Lee KP, Boyd EA, Holroyd-Leduc JM, Bacchetti P, Bero LA. Predictors of publication: Characteristics of submitted manuscripts associated with acceptance at major biomedical journals. Medical Journal of Australia. 2006; 184(12): 621-626. DOI: https://doi.org/10.5694/j.1326-5377.2006. tb00418.x

13. Skarupski KA. Wag Your Work: Writing Accountability Groups Bootcamp for Increasing Scholarly Productivity. CreateSpace Independent Publishing Platform; 2018.

How to cite this article: Ittenbach RF, Ittenbach WA. Writing for Publication in Informatics and Data Science in Clinical Research Journal of the Society for Clinical Data Management. 2021; 1(1): 9, pp.1-6. DOI: https://doi.org/10.47912/jscdm.32

Copyright: (c) 2021 SCDM publishes JSCDM content in an open access manner under a Attribution-Non-Commercial-ShareAlike (CC BY-NC-SA) license. This license lets others remix, adapt, and build upon the work non-commercially, as long as they credit SCDM and the author and license their new creations under the identical terms. See https://creativecommons.org/licenses/by-nc-sa/4.0/. 